\title{
Direct Analysis of Liquid Samples by Desorption Electrospray Ionization-Mass Spectrometry (DESI-MS)
}

\author{
Zhixin Miao and Hao Chen \\ Center for Intelligent Chemical Instrumentation, Department of Chemistry and Biochemistry, Ohio \\ University, Athens, Ohio, USA
}

\begin{abstract}
Desorption electrospray ionization-mass spectrometry (DESI-MS) was evaluated for the direct analysis of liquid samples. Several interesting results were found. First, in contrast to the previous DESI analysis of dried solid samples that was limited to proteins with $\mathrm{MW} \leq 25 \mathrm{kDa}$ (Anal. Chem. 2007, 79, 3514), bovine serum albumin (BSA, $66 \mathrm{kDa}$ ) was successfully ionized from solutions by DESI with observation of corresponding multiply charged ions. Second, direct DESI analysis of protein tryptic digest solutions without chromatographic separation, sample clean-up, and the sample drying step was demonstrated, providing reasonably good sequence coverage of $52 \%$ to $97 \%$. Third, direct analysis of biofluids such as an undiluted urine sample without sample pretreatment is possible, emphasizing the high tolerance of DESI with salt. These results suggest that a charged droplet pick-up mechanism is responsible for desorption and ionization of liquid samples by DESI. Also, unlike in electrospray ionization (ESI), inhibition of electrochemical reduction in the negative ion mode was observed for liquid sample DESI. In addition, reactive DESI can be performed with ion/ion reactions of $\mathrm{Zn}$ (II) complexes for the selective binding of phosphoserine in the presence of serine. DESI experiment can also be carried out directly to liquid samples flowing out of a pumped syringe needle tip, allowing rapid analysis. Furthermore, on-line coupling of electrochemical cell with DESI-MS was demonstrated, in which perylene radical cations generated in the cell were successfully transferred to the gas-phase for MS detection by DESI. This study extended the scope of DESI-MS applications, which could have potentials in bioanalytical and forensic analysis. (J Am Soc Mass Spectrom 2009, 20, 10-19) (c) 2009 Published by Elsevier Inc. on behalf of American Society for Mass Spectrometry
\end{abstract}

A mbient mass spectrometry (MS) [1] is of great value because it allows the analysis of samples with little or no sample preparation. Nowadays, a number of ambient ionization methods [2-16] have been introduced as rapid tools to provide efficient desorption, ionization, and further mass spectrometric characterization of target compounds. As a representative ambient ionization method, desorption electrospray ionization (DESI) has become very successful in the fast analysis of a variety of different analytes including pharmaceuticals [17-19], metabolites [20, 21], drugs of abuse [22, 23], explosives [24-26], chemical warfare agents [27], and even intact tissues [28, 29] as well as thin-layer chromatography plate [30]. In the DESI experiments, ionization occurs via the interaction of charged microdroplets generated in a pneumatically assisted electrospray of an appropriate solvent with samples placed on surfaces. Typically, solid samples on the surface are desorbed and ionized during DESI-MS analysis, and liquid samples typically undergo drying

Address reprint requests to Dr. Hao Chen, Center for Intelligent Chemical Instrumentation, Department of Chemistry and Biochemistry, Ohio University, Athens, OH, USA. E-mail: chenh2@ohio.edu on surface in air before ionization. One practical reason for this is that liquid samples could be blown away from the surface immediately (i.e., splashing of liquids) by the high-velocity nebulizing gas employed for the generation of charged microdroplets. As a consequence, the resulting ion signal, if any, will not last long. Recently, two novel sample introduction methods have been reported for the analysis of solution samples either using DESI or DeSSI. One is to add aqueous samples onto a cotton swab or filter paper followed by DESI analysis [31, 32]. The other is to use a permeable membrane to enrich analytes from solutions, which can be desorbed and ionized from the other side of the membrane after penetrating the membrane [33].

This study presents a new DESI method for the direct analysis of liquid samples on surface, which are continuously driven through a silica capillary by a syringe pump onto a surface (in this way the issue of liquid splashing mentioned before can be overcome; see the prototype apparatus illustrated in Figure 1). The analysis of liquid samples using DESI was initially motivated by two reasons: (1) many biological samples such as urine and blood occur in liquid phase; a direct analysis method for liquids without drying samples on
(C) 2009 Published by Elsevier Inc. on behalf of American Society for Mass Spectrometry. 1044-0305/09/\$32.00

doi:10.1016/j.jasms.2008.09.023
Published online September 30, 2008 Received July 16, 2008 Revised September 18, 2008 Accepted September 24, 2008 


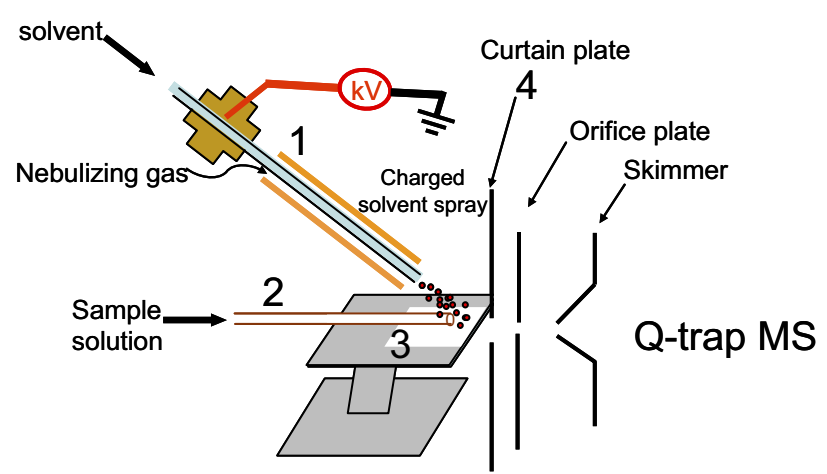

Figure 1. Schematic showing the DESI-MS apparatus for the direct analysis of liquid samples. 1: ESSI source; 2: sample introduction silica capillary (this capillary can be replaced by a syringe needle so that liquid samples can be delivered to the surface directly from a pumped syringe, as demonstrated later in the text); 3: porous Teflon surface; 4: curtain plate of Q-trap instrument.

the surface is thereby desirable because it would allow sample detection from their native environments and could further speed up DESI analysis process; (2) capability for liquid analysis will allow DESI to be coupled with other devices such as electrochemical cells or separation technologies for novel analytical applications. During the evaluation course of this method, a number of samples were examined, including amino acid, peptide, and protein solutions as well as protein digests and biological fluids such as raw urine. It turns out that desorption and ionization of liquid samples by DESI in this study is effective and sensitive. In contrast to the previous DESI experiments of detecting dried protein samples on surface [34], high-mass proteins ( $>25 \mathrm{kDa}$ ) can be ionized directly from solutions, expanding the scope of DESI in ionization of biological macromolecules. Also, efficient ionization of peptides from protein digests and of methamphetamine (a drug of abuse) from raw urine without chromatographic separation, sample clean-up, and drying in air can be carried out using this method. In the negative ion mode, reduction of analyte TNT was not observed in DESI, differing from ESI analysis in which electrolysis process is inherent. In addition, reactive DESI experiments [17, 25, $26,31,35,36]$, in which reactant ions generated by spraying a solution containing specific reagents are allowed to selectively react with analytes, can be performed to ionize liquid samples to enhance detection selectivity. Furthermore, a novel application of DESI in coupling with electrochemistry was successfully demonstrated, providing a convenient method for probing species occurring in electrochemical cells.

\section{Experimental}

Amino acid, peptide and protein standards including L-arginine, L-alanine, L-serine, bradykinin, neurotensin, insulin (5.7 kDa), ubiquitin (8.5 kDa), apomyoglobin(16.9 $\mathrm{kDa}), \beta$-lactoglobulin B (18.2 kDa), $\alpha$-chymotrypsinogen A $(25.6 \mathrm{kDa})$ and bovine serum albumin (BSA, $66 \mathrm{kDa})$, methamphetamine, zinc nitrate hexahydrate, phospho- serine, phosphocholine chloride calcium salt tetrahydrate, perylene, lithium triflate, and methylene chloride were purchased from Sigma-Aldrich (St. Louis, MO) and used without further purification. 2,2'-Dipicolylamine (DPA) was purchased from TCI (Portland, OR). 2,4,6Trinitrotoluene (TNT) in solution $(1 \mathrm{mg} / \mathrm{mL}$ in methanol/ acetonitrile) was bought from Accustandard (New Haven, CT). The deionized water used for sample preparation was obtained using a Nanopure Diamond Barnstead purification system (Barnstead International, Dubuque, IA). High-performance liquid chromatography grade methanol and acetonitrile were purchased from GFS Chemicals (Columbus, $\mathrm{OH}$ ), and glacial acetic acid was purchased from Fisher Chemicals (Fair Lawn, NJ). Porous Teflon was purchased from Small Parts (Miramar, FL).

Ubiquitin was digested using the following protocol. $250 \mu \mathrm{L}$ of $2 \mu \mathrm{g} / \mathrm{mL}$ ubiquitin solution in $25 \mathrm{mM}$ $\mathrm{NH}_{4} \mathrm{HCO}_{3}, 150 \mu \mathrm{L}$ of $25 \mathrm{mM} \mathrm{NH} \mathrm{NCO}_{3}$ solution in water, and $100 \mu \mathrm{L}$ of $0.1 \mu \mathrm{g} / \mathrm{mL}$ trypsin in $50 \mathrm{mM}$ acetic acid were mixed. After the mixture was incubated in $37^{\circ} \mathrm{C}$ water bath overnight, the incubation sample was quenched by adding $150 \mu \mathrm{L}$ of $1 \%$ TFA. For the BSA digestion, the same protocol was followed except that half volume of each solution was used.

All of the DESI experiments were carried out using an electrosonic spray ionization (ESSI) [37] source to generate charged microdroplets. The spray voltage was set at +4.5 to $5.5 \mathrm{kV}$ for the positive ion mode and -4.5 $\mathrm{kV}$ for the negative ion mode and the nebulizing gas $\left(\mathrm{N}_{2}\right)$ pressure for ESSI was 160 psi. Unless otherwise specified, the solvent for ESSI typically consisted of methanol/water with either $0.5 \%$ or $1 \%$ acetic acid and was injected at a flow rate of $10 \mu \mathrm{L} / \mathrm{min}$. A home-built aluminum platform was used to support a porous Teflon surface onto which liquid samples were continuously introduced for ionization through a silica capillary (i.d. $0.1 \mathrm{~mm}$ ) by using a Chemyx model F100 syringe pump (Huston, TX) at a flow rate of 0.1 to 5 $\mu \mathrm{L} / \mathrm{min}$ (direct ionization of liquid samples emerging out of a syringe needle by DESI is also possible, which decreases the time for sample introduction). For preparation of liquid sample solutions, amino acids and peptides were dissolved in methanol/water (1:1 by volume) and proteins were dissolved in methanol/ water/acetic acid (1:1:0.005 by volume). All of the amino acid, peptide, protein solutions, as well as protein digest solutions and raw urine samples spiked with methamphetamine were directly subjected for DESI analysis without drying in air. The ESSI sprayer was aimed to the outlet of the sample introduction silica capillary with an optimal spray impact angle of $30^{\circ} \sim 45^{\circ}$. The vertical and horizontal distances between the sprayer and the capillary outlet were $\sim 0.5 \mathrm{~mm}$ and $0.5 \mathrm{~mm}$, respectively, (to overcome the influence of the counter-flow curtain gas from the instrument interface, which makes the emerging liquid from the capillary flow backward, the ESSI sprayer is positioned slightly behind the silica capillary outlet by ca. $0.5 \mathrm{~mm}$ in the 
horizontal level). A capillary outlet-to-curtain plate aperture distance of 1 to $2 \mathrm{~mm}$ was used. The ions generated by DESI were collected and detected by a hybrid triple-quadrupole-linear ion trap mass spectrometer (Q-trap 2000; Applied Biosystems/MDS SCIEX, Concord, Canada). Curtain gas $\left(\mathrm{N}_{2}\right)$ was kept as 20 (manufacturer's units) and declustering potential was 5 to $80 \mathrm{~V}$. Collision induced dissociation (CID) was carried out to provide ion structural information using either enhanced product ion scan mode or product ion scan mode. Nitrogen gas was used as collision gas. Data acquisition was performed using the Analyst software (Version 1.4.2, Applied Biosystems/MDS SCIEX, Concord, Canada). Deconvolution of mass spectra was carried out using MagTran 1.03b2 software (Amgen Inc., Thousand Oaks, CA) written based on the ZScore algorithm [38]. ESI experiments carried out for comparison purpose were performed using a commercial TurbolonSpray ion source (Applied Biosystems/MDS SCIEX, Concord, Canada) with an injection flow rate of $10 \mu \mathrm{L} / \mathrm{min}$.

For the on-line coupling of electrochemistry with DESIMS, a tubular electrode flow-through cell [39] was used, which simply consisted of two stainless steel metal capillaries $(6 \mathrm{~cm}$ long, $127 \mu \mathrm{m}$ i.d., $1.58 \mathrm{~mm}$ o.d.) bridged by a polyetheretherketone (PEEK) union. A $0.1 \mathrm{mM}$ perylene solution was prepared in a mixed solvent of $\mathrm{CH}_{3} \mathrm{CN}$ and $\mathrm{CH}_{2} \mathrm{Cl}_{2}$ (1:1 by volume) containing $40 \mathrm{mM}$ lithium triflate (added as electrolytes) and was infused into the tubular electrode cell by a pumped syringe at a flow rate of 10 $\mu \mathrm{L} / \mathrm{min}$. A DC potential of $10 \mathrm{~V}$ was applied to the cell for electrolysis. The anode metal capillary was bent in a way such that its flat end can serve as a horizontal planar surface for direct DESI desorption of the solution exiting the anode electrode from the cell.

\section{Results and Discussion}

As illustrated in Figure 1, ionization of liquid samples by DESI comes from the interaction between ESSIgenerated charged microdoplets and the sample flowing out of the silica capillary. Unlike the traditional DESI ion source, there is no need for 3D linear moving stages in our experiments; the positions of the ESSI source and the sample introduction silica capillary are fixed, simplifying the apparatus. Previously, most of the DESI experiments were performed using an instrument with a heated metal transfer capillary interface (e.g., Thermo LTQ mass spectrometer). This study is an example of adapting DESI ion source on a mass spectrometer with a counter-flow curtain gas interface. Curtain gas used serves for ion desolvation and instrument protection. After the construction of this experimental apparatus, various liquid samples were examined, as discussed below.

\section{Amino Acid and Peptide Analysis}

Amino acids and peptides in solutions were first chosen for direct DESI analysis. In the case of amino acids of arginine and alanine, the corresponding protonated molecules were observed at $\mathrm{m} / \mathrm{z} 175$ and 90 , respectively (Figures S-1a and S-1b, in Supplementary Materials, which can be found in the electronic version of this article). For bradykinin, the doubly charged ion $(\mathrm{m} / \mathrm{z}$ 531) was detected while both doubly $(\mathrm{m} / \mathrm{z}$ 837) and triply charged ions $(m / z 558)$ were seen for neurotensin (Figures S-1c and S-1d). These charge numbers are similar to those typically observed in the ionization of the corresponding compounds by ESI or in the ionization of dried samples using traditional DESI. Table 1 summarizes the solution concentration, solution injection rate, and total amount injected for the collected mass spectra mentioned above. It can be seen that this method is sensitive. For instance, good signal $(\mathrm{S} / N>$ 16, Figure S-1c) was obtained for bradykinin solution $(0.1 \mu \mathrm{g} / \mathrm{mL})$ even with the injected peptide amount of $0.2 \mathrm{ng}(0.19 \mathrm{pmol})$. Typically, analyte ion signals were detected continuously as the samples were continuously introduced onto the surface (see the inset of Figure S-1a). As previously proposed [2, 3], chemical sputtering, charge-transfer and droplet pick-up mechanisms might be involved in the DESI ionization process. In our experiments, the ESI-like spectra obtained for amino acids and peptides suggest the formation of

Table 1. Results of the DESI analysis of amino acids, peptides, and proteins in solution

\begin{tabular}{|c|c|c|c|c|c|c|c|}
\hline & $\begin{array}{c}\text { Concentration } \\
(\mu \mathrm{g} / \mathrm{mL})\end{array}$ & $\begin{array}{l}\text { Injection } \\
\text { flow rate } \\
\text { ( } \mu \mathrm{L} / \mathrm{min})\end{array}$ & $\begin{array}{c}\text { Amount } \\
\text { used }^{\mathrm{a}}\end{array}$ & $\begin{array}{c}\text { Charge } \\
\text { states } \\
\text { observed }\end{array}$ & $\begin{array}{c}\text { Theoretical } \\
\text { molecular } \\
\text { weight (Da) }\end{array}$ & $\begin{array}{c}\text { Measured } \\
\text { molecular } \\
\text { weight }(\mathrm{Da})^{\mathrm{b}}\end{array}$ & $\begin{array}{l}\text { Relative } \\
\text { error (\%) }\end{array}$ \\
\hline Arginine & 1 & 1 & $0.1 \mathrm{ng}$ & +1 & - & - & - \\
\hline Alanine & 1 & 5 & $0.9 \mathrm{ng}$ & +1 & - & - & - \\
\hline Bradykinin & 0.1 & 5 & $0.2 \mathrm{ng}$ & +2 & - & - & - \\
\hline Neurotensin & 10 & 5 & $65 \mathrm{ng}$ & $+2,+3$ & - & - & - \\
\hline Insulin & 3.1 & 0.1 & $8.8 \mathrm{ng}$ & +4 to +6 & 5733 & 5734 & 0.017 \\
\hline Ubiquitin & 100 & 5 & $0.35 \mu \mathrm{g}$ & +6 to +9 & 8565 & 8565 & 0 \\
\hline Apomyoglobin & 100 & 5 & $0.4 \mu \mathrm{g}$ & +12 to +27 & 16952 & 16958 & 0.035 \\
\hline$\beta$-Lactoglobulin B & 100 & 5 & $6 \mu \mathrm{g}$ & +12 to +18 & 18278 & 18284 & 0.033 \\
\hline$\alpha$-Chymotrypsinogen A & 100 & 5 & $4.4 \mu \mathrm{g}$ & +16 to +20 & 25657 & 25661 & 0.016 \\
\hline BSA & 200 & 5 & $3.7 \mu \mathrm{g}$ & +40 to +62 & 66431 & 66777 & 0.52 \\
\hline
\end{tabular}

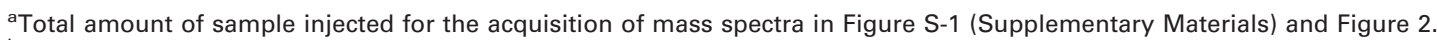

bobtained from the deconvoluted mass spectra shown in the insets of Figure 2. 
charged droplets containing analyte species [3]. Likely, droplet pick-up mechanism rather than other possible mechanisms is responsible for solution sample ionization in this study as the ionization comes from the interaction of charged microdroplets and liquid sample droplets emerging out of the silica capillary. Presumably, the merging of the sprayed charged droplets and the neutral liquid sample droplets occurs to form secondary charged droplets containing analyte compounds, which undergo desolvation to produce ions eventually. Additional evidences to support this postulation will be provided later.

\section{Protein Analysis}

Application of DESI-MS as an analysis tool for protein molecules in the field of proteomics is ideal due to its simplicity and speed of analysis for high-throughput applications. However, among the extensive applications of DESI-MS, limited attention [2, 40] has been given to the detection of proteins, especially high molecular weight proteins. A recent report by Basile et al.
[34] shows that traditional DESI on ionizing dried protein samples on surface can be a viable approach to the analysis of intact proteins up to $18 \mathrm{kDa}$. However, proteins above $25 \mathrm{kDa}$ generated poorly defined DESImass spectra with low intensity. For instance, in the analysis of bovine serum albumin (BSA, $66 \mathrm{kDa}$ ), even as the surface concentration was increased to $80 \mu \mathrm{g} /$ $\mathrm{mm}^{2}$, the $\mathrm{S} / \mathrm{N}$ of spectra did not improve above 3. In this study, by dissolving proteins in solution and then analyzing them directly from solution by DESI, highmass proteins such as BSA can be ionized and detected.

In our experiments, a set of proteins with a wide molecular weight range from 5.7 to $66 \mathrm{kDa}$ were tested, including insulin, ubiquitin, apomyoglobin, $\beta$-lactoglobulin $\mathrm{B}$, $\alpha$-chymotrypsinogen A, and BSA. As shown in the DESI spectra obtained (Figure 2), multiply charged ions were detected from the DESI ionization of solutions for all of the proteins tested, which is also similar to those seen in the ionization of dried samples using traditional DESI $[2,34,40]$. Some of experimental conditions, such as the sample concentration, the injection rate and total amount injected for the acquisition of the spectra (Fig-

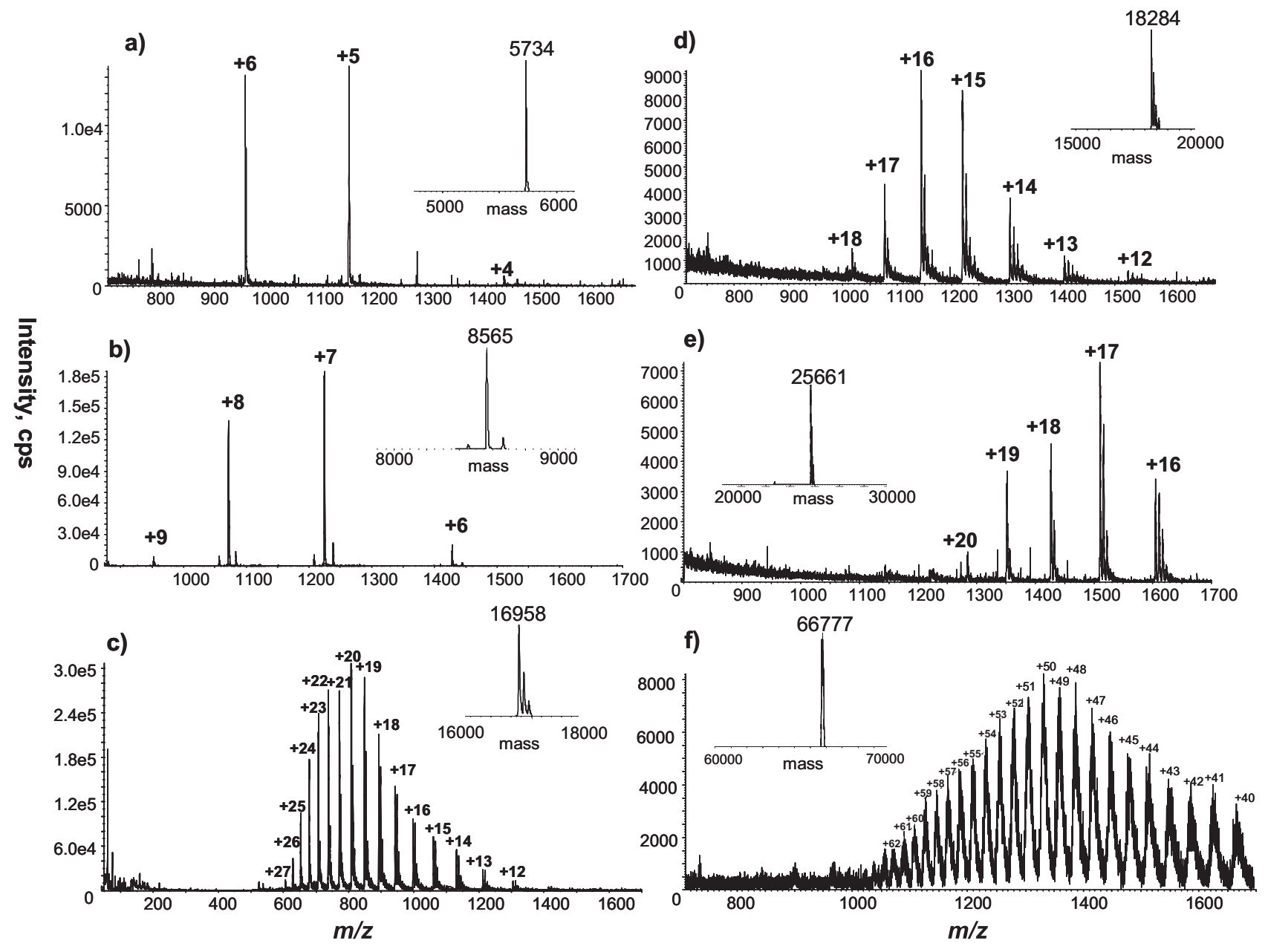

Figure 2. MS spectra showing the direct DESI-MS analysis of solutions containing (a) insulin, (b) ubiquitin, (c) apomyoglobin, (d) $\beta$-lactoglobulin B, (e) $\alpha$-chymotrypsinogen A, and (f) BSA. The insets show the corresponding deconvoluted spectra. 
ure 2) as well as protein ion charge distributions and mass measurement accuracies are also listed in Table 1. In the case of insulin, good ion signal $(S / N>20$, Figure 2a) was observed at the total injected amount of $8.8 \mathrm{ng}$ (1.5 pmol), suggesting the good sensitivity of this method. In addition, as shown in Table 1, accurate mass measurement $(<0.04 \%)$ was obtained for proteins with molecular weight up to $25.6 \mathrm{kDa}$. In the case of BSA, ion signal with $S / N=16$ (Figure $2 \mathrm{f}$ ) was achieved at the total injected amount of $3.7 \mu \mathrm{g}$ (56 pmol). The relatively large mass measurement error $(0.52 \%)$ for BSA observed in this study might not be attributable to poor accuracy of DESI-MS but caused by the inherent heterogeneity of BSA proteins [41], as indicated by previous ESI experiments [42-45] showing the measured molecular weights of BSA ranging from $65 \mathrm{kDa}$ to $67 \mathrm{kDa}$. In this study, proteins with higher mass than BSA were not tested due to the limited mass range of our instrument (from $m / z 5$ to 1700).

The reason that big proteins can be desorbed and ionized from solutions by DESI is likely to be attributed to the smaller interactions among protein molecules in diluted solution environment compared with those in the dried proteins on surface. It is well known that aggregation [46] for proteins can occur at high concentrations due to large intermolecular interactions, which leads to the loss of activity of proteins. Aggregated proteins, especially those with high molecular weight, are possibly difficult to be desorbed from surface. The capability of ionizing high-mass proteins from solutions by DESI-MS as introduced in this study could have significant potentials in biological analysis.

\section{Protein Digest Analysis}

Identification of proteomics by mass spectrometric analysis of protein enzymatic digests (the "bottom-up" approach) has become one of the most important applications of MS. Traditional bottom-up protocols involve a chromatographic separation or sample clean-up before the digest peptide mixtures are introduced into a mass spectrometer for ionization. In contrast, as previously reported, DESI requires no separation or sample clean-up for the analysis of protein digests, and samples can be analyzed after drying on the surface [2, 3, 47]. In this study, our results show that DESI can also be used for direct analysis of protein enzymatic digests even without the step of drying samples in air.

A couple of proteins such as ubiquitin and BSA were digested separately using trypsin enzyme in the buffer of $\mathrm{NH}_{4} \mathrm{HCO}_{3}$, following the reported procedure in [47]. Then direct DESI analysis was applied to the digests without dilution, sample clean-up, or drying. It was found that 12 peptides were identified from the mass spectrum of ubiquitin digest, and most of the peptides produced singly charged molecule ions (Figure S-2, Supplementary Materials). These peptides contain 74 out of 76 amino acids of ubiquitin, corresponding to a high sequence coverage of $97 \%$. Tandem mass spectrometry was used to confirm the peak assignments. For example, CID of the protonated ion [TLTGK $+\mathrm{H}]^{+}(m / z 519)$ yields the fragment ions of $y_{2}, y_{3}$, and $b_{2}$, confirming its structure. In the case of BSA digest (Figure S-3, Supplementary Materials), 60 peptide ion peaks corresponding to 53 different peptides were observed and identified (the $m / z$ values, charge states and sequences of the identified peptides are listed in Table S-1, Supplementary Materials), providing a 52\% sequence coverage of BSA, which is higher than the previously reported coverage of $24 \%$ using DESI for the analysis of dried BSA tryptic digest on surface [47]. Again, these results might be contributed to the easier desorption of samples from solutions than from solid phase during DESI ionization. Compared with previous work [2, 3, 47] of using DESI for analysis of protein digests, the current method does not involve the sample drying step, thus further expediting the whole analysis process. Once sample solutions are introduced onto the surface, the sample ions are detected within seconds.

\section{Urine Analysis-Direct Monitoring of Drugs of Abuse in Urine}

Being capable of analyzing biological fluids without sample workout is another strength of DESI-MS. Previously, several reports about DESI analysis of dried urine samples were published [35, 48, 49]. In this study, we employed DESI for direct monitoring of methamphetamine, a common drug of abuse with MW 149 Da (see its structure in Figure 3a), in raw urine.

Analytical methods previously reported to analyze drugs of abuse in human urine samples include GC/MS [50], high-performance liquid chromatography (HPLC) [51], capillary electrophoresis (CE) [52], and CE-MS [53], which involved time-consuming sample extraction, derivatization, or separation. In our experiments, methamphetamine-spiked raw urines were directly ionized using DESI. Figure 3a depicts the mass spectrum obtained from the DESI ionization of a raw urine sample containing $20 \mu \mathrm{g} / \mathrm{mL}$ of methamphetamine, with the DESI spray solvent being methanol/water/ acetic acid (1:1:0.005 by volume). It can be seen that the methamphetamine can be easily detected as the base peak at $\mathrm{m} / \mathrm{z} 150$ corresponding to the protonated molecule ion [methamphetamine $+\mathrm{H}]^{+}$. CID of the ion of $m / z 150$ gives rise to fragment ion at $m / z 119$ and 91 by consecutive loss of $\mathrm{CH}_{3} \mathrm{NH}_{2}$ and $\mathrm{C}_{2} \mathrm{H}_{4}$, confirming the ion structure. Other urea-related peaks are also well observed, including [2urea $+\mathrm{H}]^{+}(m / z$ 121), [2urea + $\mathrm{Na}^{+}(m / z \text { 143), [2urea }+\mathrm{K}]^{+}(m / z$ 159), in agreement with the fact that urine contains abundant salts and urea. Surprisingly, the high intensity signal of the ion [methamphetamine $+\mathrm{H}]^{+}(\mathrm{m} / z$ 150) can last for more than 14 min (Figure 3b), strongly indicating the high tolerance of DESI-MS to salts [49]. However, when the concentration of methamphetamine spiked in urine was lowered down to $1 \mu \mathrm{g} / \mathrm{mL}$, the ion signal at $\mathrm{m} / \mathrm{z} 150$ 

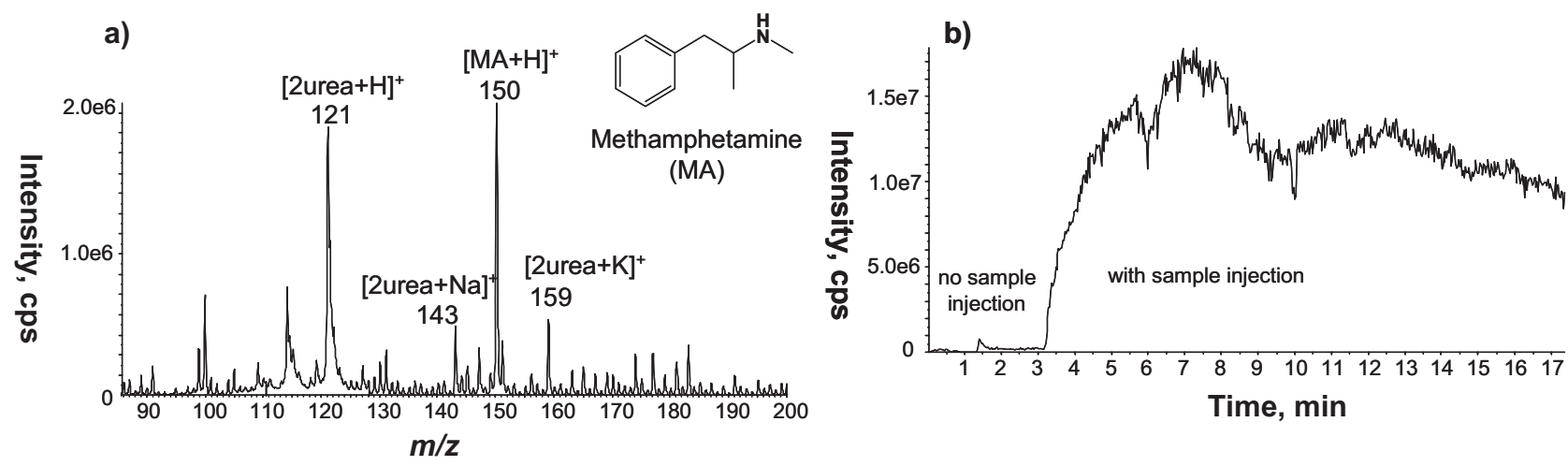

c)

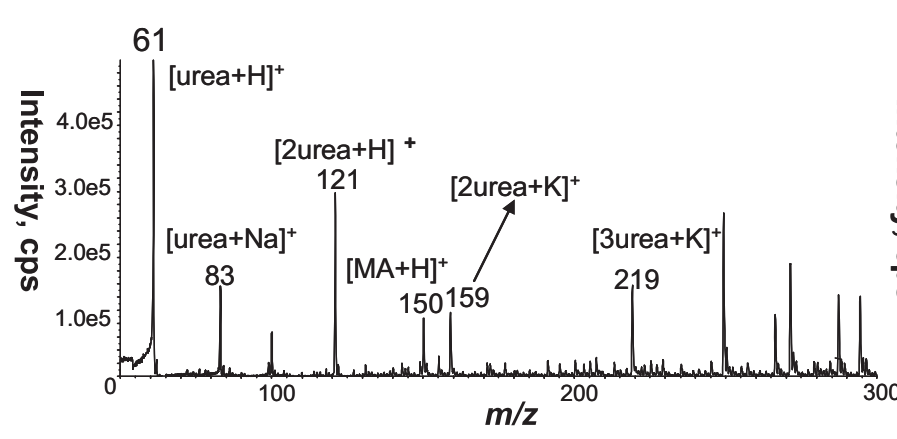

d)

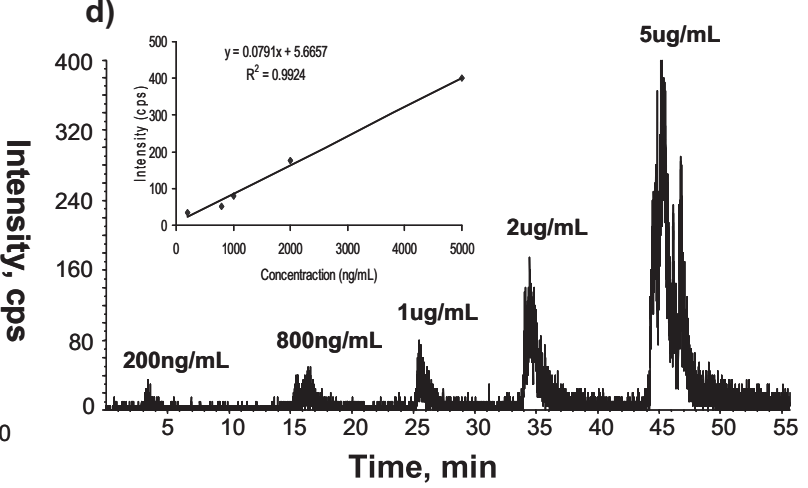

Figure 3. (a) MS spectrum showing the DESI-MS detection of methamphetamine $(20 \mu \mathrm{g} / \mathrm{mL})$ in a raw urine solution; DESI spray solvent used was methanol/water/acetic acid (1:1:0.005 by volume); (b) the extracted ion chromatogram for the protonated methamphetamine ion of $\mathrm{m} / \mathrm{z} 150$; (c) MS spectrum showing the DESI-MS detection of methamphetamine $(1 \mu \mathrm{g} / \mathrm{mL})$ in a raw urine solution; DESI spray solvent used was methanol/acetic acid (1:0.03 by volume); and (d) DESI-MS responses (total ion chromatogram) obtained using SRM (the dissociation of $\mathrm{m} / \mathrm{z} 150$ into $\mathrm{m} / \mathrm{z}$ 91) monitoring of methamphetamine in urine. The inset shows the DESI-MS response as a function of concentration of methamphetamine in urine.

disappeared (spectrum not shown), probably due to the suppression effect from abundant basic urea in the sample. Interestingly, as we changed the DESI spray solvent to methanol/acetic acid (1:0.03 by volume), the signal recovered (Figure 3c). Overcoming the suppression effect by adding more acid indicates that the droplet pick-up rather than chemical-sputtering or charge-transfer mechanism mentioned before plays the major role in the ionization by DESI on liquid samples. Probably, with an increased amount of acids in ESSI spray solvent, the resulting secondary charged droplets from the combination of the primary ESSI-generated charged droplets and liquid sample will have an increased number of protons available to the analyte methamphetamine; thus protonation of methamphetamine still can occur.

We also tested direct ionization of urine by normal electrospray ionization (ESI) but failed to observe the protonated methamphetamine for the urine containing $1 \mu \mathrm{g} / \mathrm{mL}$ of methamphetamine (Figure S-4a, Supplementary Materials). Even when the same sample was diluted by methanol with addition of acetic acid, the ion of $m / z 150$ was barely seen in the ESI spectrum (Figure $\mathrm{S}-4 \mathrm{~b}$, Supplementary Materials). In comparison to the DESI results mentioned above, it suggests that DESI has better performance (i.e., higher tolerance to salts) than ESI in terms of direct ionization of such a biological fluid containing high concentration of salts, which is in agreement with previous DESI study [49].

Quantitation is also possible for direct urine monitoring, as illustrated in Figure 3d, showing the total ion chromatogram obtained using SRM monitoring of the dissociation of $\mathrm{m} / \mathrm{z} 150\left([\text { methamphetamine }+\mathrm{H}]^{+}\right)$into $\mathrm{m} / \mathrm{z}$ 91. A linear DESI-MS response as a function of solution concentrations of methamphetamine (200 $\mathrm{ng} / \mathrm{mL}$ to $5 \mu \mathrm{g} / \mathrm{mL}$ ) in raw urine was obtained with a good linear regression coefficient $\left(R^{2}=0.992\right.$, Figure 3d inset). The detection of limit for methamphetamine in urine $(\mathrm{S} / \mathrm{N}=3)$ obtained in this study is $200 \mathrm{ng} / \mathrm{mL}$, which is lower than the cutoff concentration of 1000 $\mathrm{ng} / \mathrm{mL}$ by immunoassay and the cutoff of $500 \mathrm{ng} / \mathrm{mL}$ by GC/MS [54], suggesting the possibility of using this method for practical forensic analysis.

\section{Reduction Inhibition in Liquid DESI}

Another difference between traditional ESI and liquid sample DESI was also noted with regard to the ionization of electron deficient compounds such as TNT. It 


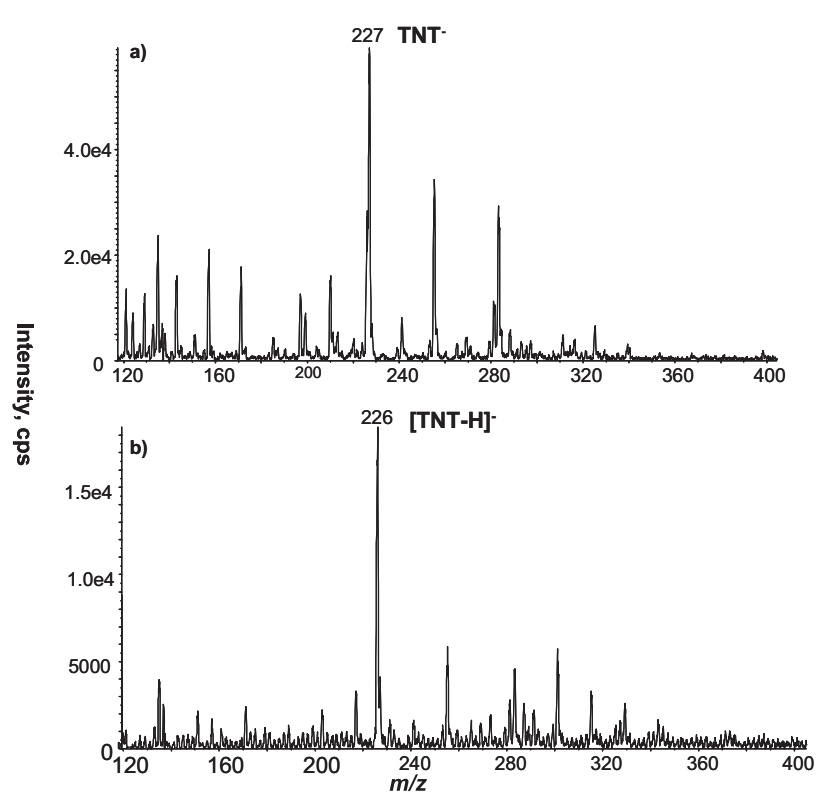

Figure 4. (a) ESI-MS spectrum and (b) DESI-MS spectrum of 10 $\mu \mathrm{g} / \mathrm{mL}$ of TNT in methanol/acetonitrile (1:1 by volume) in the negative ion mode. Note that ESI produces the radical anion TNT ${ }^{-}$. $(m / z 227)$ due to reduction while DESI yields deprotonated species $[\mathrm{TNT}-\mathrm{H}]^{-}(\mathrm{m} / \mathrm{z} 226)$. The spray solvent for ESSI used in DESI was methanol/water (1:1 by volume).

was found that ESI of TNT solution $(10 \mu \mathrm{g} / \mathrm{mL}$ in methanol/acetonitrile) in the negative ion mode produces the radical anion $\mathrm{TNT}^{-}$of $\mathrm{m} / \mathrm{z} 227$ (Figure 4a).This is probably due to the reduction of TNT (i.e., electron capture) in the ESI source in which electrolysis is inherent [55-57]. In the liquid sample DESI experiment, the reduction did not occur; instead, deprotonation occurred to form the ion [TNT $-\mathrm{H}]^{-}$of $\mathrm{m} / \mathrm{z} 226$ (Figure $4 \mathrm{~b}$ ). The inhibition for reduction in liquid sample DESI might be because no voltage was directly applied to the sample solution in DESI, unlike in the ESI experiment. Interestingly, the result of liquid sample DESI is also in contrast to that of solid sample DESI [24] which used dried TNT sample but was shown to generate the radical anion $\mathrm{TNT}^{-\cdot}$ under similar experimental conditions. The electron capture of TNT in the solid sample DESI was rationalized by the possible corona discharge mechanism since there was a high voltage applied to ESSI probe used in DESI source. By comparison, it can be seen that the inhibition of reduction in liquid sample DESI is likely to be ascribed to the solvation of TNT in the sample, which prevents the occurrence of heterogeneous phase electron transfer from gaseous anions (in the DESI source), if any, to the TNT dissolved in solution.

\section{Reactive DESI}

Reactive DESI [17, 25, 26, 31, 35, 36] is an additional development of DESI method that greatly improves the selectivity and efficiency with which compounds with specific functionalities are detected. It is the use of a DESI spray solution that contains specific reagents intended to allow particular ionic reactions (e.g., ion/molecule reactions) during the sampling process. In addition to enhancing selectivity for chemical analysis, reactive DESI also provides a platform for the study of ionic reactions involving heavy and polar reactants, expanding the scope of the ion chemistry study performed in vacuum, which requires volatile neutral reactants $[58,59]$.

The current DESI method for analyzing liquid samples also allows one to perform reactive DESI experiments. In this study, we investigated reactive DESI in which compounds containing phosphate groups in solutions, such as phosphocholine and phosphoserine, were ionized via the selective binding with $\mathrm{Zn}$ (II) complex ions. $[\mathrm{Zn}(\mathrm{DPA})]^{2+}$ is a well-known phosphate binding motif, which has been used as a recognition element of phosphate in the construction of chemical sensors [60, 61]. In the experiment, instead of spraying only solvent on the sample surface, an aqueous solution containing $\mathrm{Zn}\left(\mathrm{NO}_{3}\right)_{2}$ $(0.06 \mathrm{mM})$ and DPA $(0.03 \mathrm{mM})$ was sprayed. One of the major resulting ions from the spray is $\left[\mathrm{Zn}(\mathrm{DPA})\left(\mathrm{NO}_{3}\right)\right]^{+}$ $(\mathrm{m} / \mathrm{z}$ 325). As the sprayed charged microdroplets containing reactant ions $\left[\mathrm{Zn}(\mathrm{DPA})\left(\mathrm{NO}_{3}\right)\right]^{+}$aim to a solution of phosphocholine $(1 \mathrm{mM})$ flowing out of the silica capillary, a product ion at $m / z 445$ (Figure 5a) arises, corresponding to the complex ion $[\mathrm{Zn}(\mathrm{DPA})(\text { phosphocholine })]^{+}$. Likely, this product results from the ion/ion reaction between $\left[\mathrm{Zn}(\mathrm{DPA})\left(\mathrm{NO}_{3}\right)\right]^{+}$and the negatively charged phosphocholine $\mathrm{Me}_{3} \mathrm{~N}^{+} \mathrm{CH}_{2} \mathrm{CH}_{2} \mathrm{OPO}_{3}{ }^{2-}$ by loss of nitrate $\mathrm{NO}_{3}{ }^{-}$ (i.e., ion exchange of nitrate in the $\left[\mathrm{Zn}(\mathrm{DPA})\left(\mathrm{NO}_{3}\right)\right]^{+}$by the phosphocholine anion). Upon CID, this product dissociates into $m / z 386$ by loss of $\mathrm{Me}_{3} \mathrm{~N}$. Also, fragment ions such as $[\mathrm{DPA}-\mathrm{H}]^{+}(\mathrm{m} / \mathrm{z} 198)$ and $[\mathrm{Zn}(\mathrm{DPA})-\mathrm{H}]^{+}$ $(\mathrm{m} / \mathrm{z} 262)$ was observed, consistent with its structure.

This zinc binding chemistry is carried out to selectively ionize phosphoserine in the presence of serine. As shown in Figure $5 b$, upon ionizing a mixed aqueous solution containing $1 \mathrm{mM}$ serine and $1 \mathrm{mM}$ phosphoserine in $0.1 \%$ acidic acid (the addition of acetic acid was to prevent the deprotonation of serine to form negatively charged carboxylate), a product ion of $\mathrm{m} / \mathrm{z} 447$, corresponding to the adduct ion $[\mathrm{Zn}(\mathrm{DPA})(\text { phosphoserine }-\mathrm{H})]^{+}$, was observed. By contrast, the adduct ion [Zn(DPA)(serine $\mathrm{H})]^{+}$was not detected. This result is attributed to the selective binding of phosphate group of the phosphoserine by $[\mathrm{Zn}(\mathrm{DPA})]^{2+}$. Presumably, the formation of $[\mathrm{Zn}(\mathrm{DPA})(\text { phosphoserine }-\mathrm{H})]^{+}$is a result of an ion/ion reaction between $\left[\mathrm{Zn}(\mathrm{DPA})\left(\mathrm{NO}_{3}\right)\right]^{+}$or $\left[\mathrm{Zn}(\mathrm{DPA})\left(\mathrm{CH}_{3} \mathrm{COO}\right)\right]^{+}$(observed as the dominant ions in Figure $5 b$ ) and deprotonated phosphoserine (deprotonation of this amino acid is still possible in the presence of acetic acid due to the stronger acidity of phosphoric acid than that of acetic acid). CID of the ion $\mathrm{m} / \mathrm{z}$ of 447 shows a major fragment ion of $\mathrm{m} / \mathrm{z} 360$ by loss of a 2-aminoacrylic acid as well as a fragment ion of $[\mathrm{DPA}-\mathrm{H}]^{+}(\mathrm{m} / \mathrm{z}$ 198). These results indicate that the 


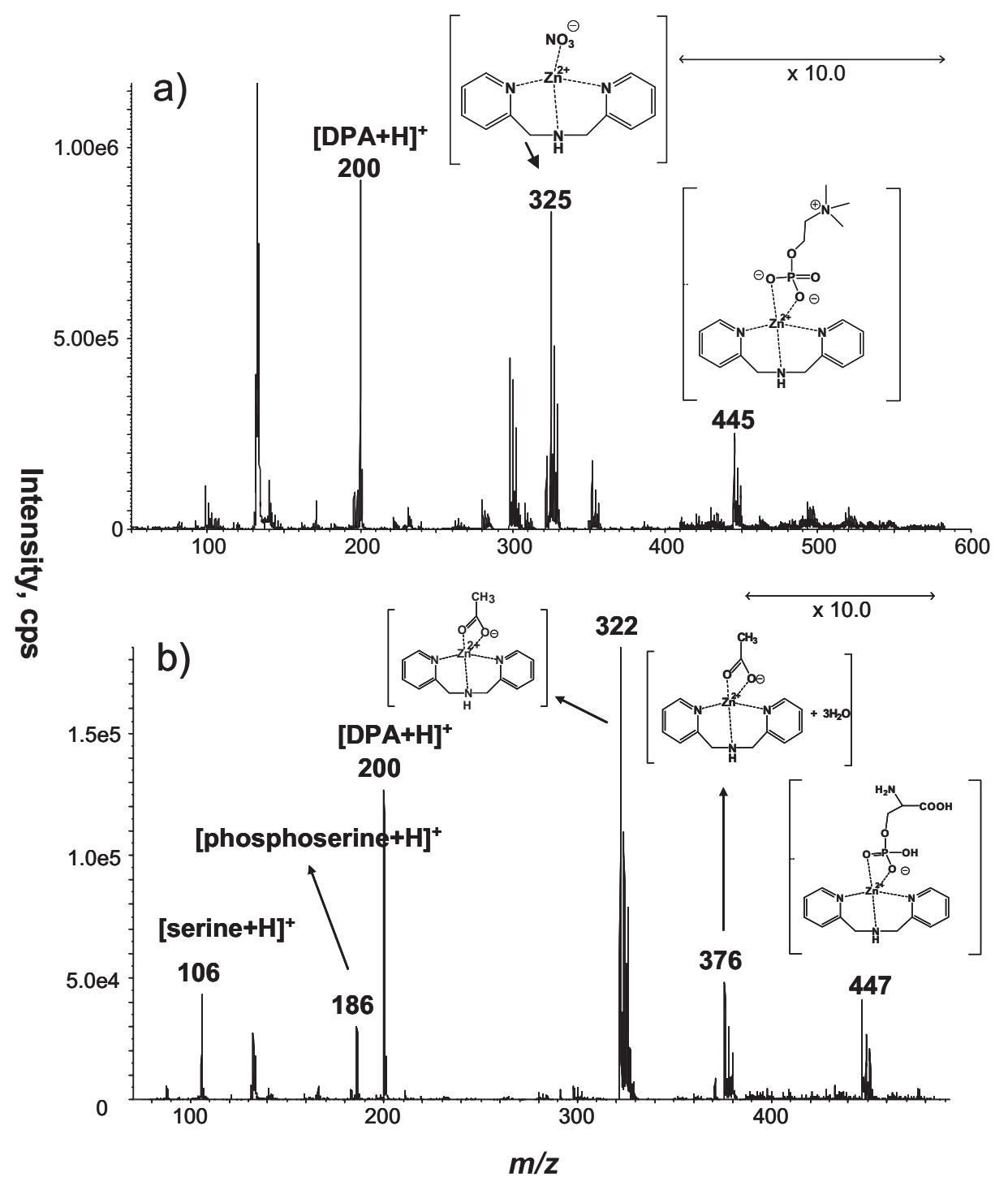

Figure 5. Reactive DESI mass spectra showing (a) the binding of phosphocholine and (b) the selective binding of phosphoserine with $\mathrm{Zn}$ (II) complex ions in the presence of serine.

reactive DESI based on the zinc chemistry might be applicable to selectively ionize phosphopeptides from phosphorylated protein digests.

\section{Direct Desorption and Ionization of Liquid Samples from a Syringe Needle Tip}

Alternatively, liquid sample introduction simply using a syringe (driven by a syringe pump) for DESI analysis is also possible. In this study, we removed the sample introduction silica capillary and carried out direct DESI analysis of liquid samples emerging out of a syringe needle tip to shorten the analysis time. For a peptide bradykinin solution tested as an example, it was found that the doubly charged peptide ion was detected $\sim 5 \mathrm{~s}$ after the syringe pump was turned on for sample introduction, reflecting the high speed feature of DESI method for chemical analysis.

\section{Coupled On-Line with Electrochemical Cell}

Combination of electrochemistry (EC) on-line with mass spectrometry has proven to be useful in the mechanistic study of redox reactions and in analytical applications. Previous coupling was realized using ionization methods such as thermospray (TS) [62], fast atom bombardment (FAB) [63], and ESI [39, 64-67]. In this study, DESI was also used for this purpose. In the previously reported studies for the combination of EC with ESI [39, 66], the EC system usually needed to be either floated or decoupled from ESI source since ESI operates at a high voltage. In the case of coupling EC with DESI-MS, the floating or decoupling is not necessary since sample solution introduced for DESI ionization is physically separated from the ESSI probe of DESI where high voltage is applied. Thus, the coupling becomes simple and sample solution flowing out of 

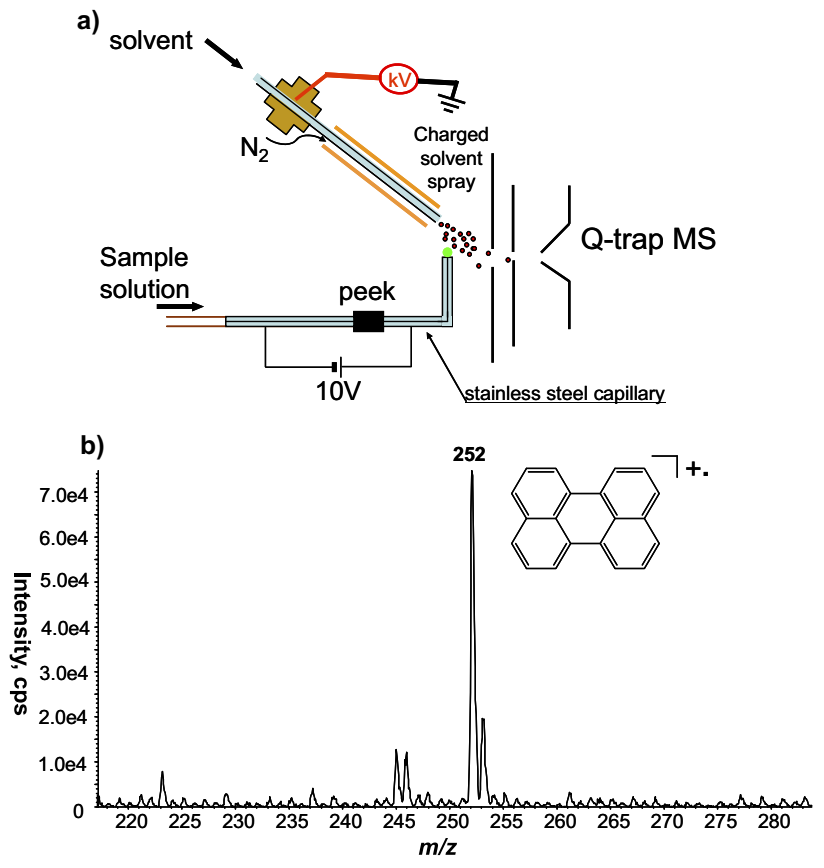

Figure 6. (a) Scheme showing the apparatus for coupling of electrochemical cell with liquid sample DESI-MS; (b) DESI mass spectrum showing the formation of perylene radical cation $(\mathrm{m} / \mathrm{z}$ 252) generated by oxidation in the electrochemical cell.

electrochemical cell can be directly examined by DESI-MS. Figure 6a shows the EC/DESI-MS apparatus used in this study (see details in the Experimental Section), and perylene, a conjugated aromatic molecule, was chosen to test the feasibility of this system. In the experiment, as the perylene solution $(0.1 \mathrm{mM})$ was infused into the tubular electrode cell to which a DC potential of $10 \mathrm{~V}$ was applied and the solution flowing out of the cell was desorbed by DESI, the perylene radical cation $(m / z 252)$ was detected (Figure $6 \mathrm{~b})$. After the DC potential was turned off, the signal of $\mathrm{m} / \mathrm{z} 252$ disappeared. It arose again when the DC potential was turned on. These results confirm that the radical cation did originate from the electrochemically oxidation in the cell rather than from DESI process (the latter just serves to transfer the formed radical cation to the gas phase for MS detection). This EC/DESI-MS coupling system is simple and could find useful analytical applications in the future, given the importance of electrochemistry.

\section{Conclusions}

As demonstrated in the paper, simply by introducing liquid samples instead of dried ones on surface for analysis, some of the DESI performances can be improved, and some novel DESI applications can be uncovered. These include a wide range for the analysis of proteins, particularly those with high molecular weight, and enhanced sequence coverage for protein digest analysis. The results probably come from the easier desorption of compounds in solution than in dried solid phase by DESI.
Based on these observations as well as the removal of suppression effect by added acids, apparently droplet pick-up mechanism is mainly responsible for the DESI ionization of liquid samples. The differences between liquid sample DESI and ESI were also noted, both in the tolerance to salt effect and in the reduction phenomenon associated with ionization. In addition, enhanced selectivity can be furnished by employing selective ion chemistry in reactive DESI experiments. Also, the coupling of electrochemical cell with DESI-MS was successfully demonstrated, which could have novel analytical applications due to the simplicity of EC/DESI-MS system and the significance of electrochemistry. Coupling with separation techniques, including chromatography, electrophoresis, and microfluidics, could also be advantageous due to the high salt tolerance of DESI, and such an investigation is underway.

\section{Acknowledgments}

The authors acknowledge support for this work by the Ohio University Startup Foundation (SU 1006172). The authors are very grateful for the supply of MagTran deconvolution software from Dr. Zhongqi Zhang and the help from Dr. Brian Laughlin, Paul Schmittauer, Bascom French, and Dr. Glen Jackson.

\section{References}

1. Cooks, R. G.; Ouyang, Z.; Takats, Z.; Wiseman, J. M. Ambient Mass Spectrometry Science 2006, 311, 1566-1570.

2. Takats, Z. W.; J. M.; Gologan, B.; Cooks, R. G. Mass Spectrometry. Sampling Under Ambient Conditions with Desorption Electrospray Ionization. Science 2004, 306, 471-473.

3. Takats, Z.; Wiseman, J. M.; Cooks, R. G. Ambient Mass Spectrometry Using Desorption Electrospray Ionization (DESI): Instrumentation, Mechanisms, and Applications in Forensics, Chemistry, and Biology. J. Mass Spectrom. 2005, 40, 1261-1275.

4. Cody, R. B.; Laramee, J. A.; Durst, H. D. Versatile New Ion Source for the Analysis of Materials in Open Air under Ambient Conditions. Anal. Chem. 2005, 77, 2297-2302.

5. Williams, J. P.; Patel, V. J.; Holland, R.; Scrivens, J. H. The Use of Recently Described Ionization Techniques for the Rapid Analysis of Some Common Drugs and Samples of Biological Origin. Rapid Commun. Mass Spectrom. 2006, 20, 1447-1456.

6. Song, Y.; Cooks, R. G. Atmospheric Pressure Ion/Molecule Reactions for the Selective Detection of Nitroaromatic Explosives Using Acetonitrile and Air as Reagents. Rapid Commun. Mass Spectrom. 2006, 20, 3130-3138.

7. Shiea, J.; Huang, M. Z.; Hsu, H. J.; Lee, C. Y.; Yuan, C. H.; Beech, I.; Sunner, J. Electrospray-Assisted Laser Desorption/Ionization Mass Spectrometry for Direct Ambient Analysis of Solids. Rapid Commun. Mass Spectrom. 2005, 19, 3701-3704.

8. Sampson, J. S.; Hawkridge, A. M.; Muddiman, D. C. Direct Characterization of Intact Polypeptides by Matrix-Assisted Laser Desorption Electrospray Ionization Quadrupole Fourier Transform Ion Cyclotron Resonance Mass Spectrometry. Rapid Commun. Mass Spectrom. 2007, 21, 1150-1154.

9. Chen, H.; Venter, A.; Cooks, R. G. Extractive Electrospray Ionization for Direct Analysis of Undiluted Urine, Milk and Other Complex Mixtures Without Sample Preparation. Chem. Commun. 2006, 19, 2042-2044.

10. McEwen, C. N.; McKay, R. G.; Larsen, B. S. Analysis of Solids, Liquids, and Biological Tissues Using Solids Probe Introduction at Atmospheric Pressure on Commercial LC/MS Instruments. Anal. Chem. 2005, 77, 7826-7831.

11. Takats, Z.; Katona, M.; Czuczy, N.; Skoumal, R. Proceedings of the 54th ASMS Conference on Mass Spectrometry and Allied Topics; Seattle, WA, May, 2006.

12. Haddad, R.; Sparrapan, R.; Eberlin, M. N. Desorption Sonic Spray Ionization for (High) Voltage-Free Ambient Mass Spectrometry. Rapid Commun. Mass Spectrom. 2006, 20, 2901-2905.

13. Haapala, M.; Pol, J.; Saarela, V.; Arvola, V.; Kotiaho, T.; Ketola, R. A.; Franssila, S.; Kauppila, T. J.; Kostiainen, R. Desorption Atmospheric Pressure Photoionization. Anal. Chem. 2007, 79, 7867-7872.

14. Ratcliffe, L. V.; Rutten, F. J. M.; Barrett, D. A.; Whitmore, T.; Seymour, D.; Greenwood, C.; Aranda-Gonzalvo, Y.; Robinson, S.; McCoustra, M. Surface Analysis under Ambient Conditions Using Plasma-Assisted Desorption/ Ionization Mass Spectrometry. Anal. Chem. 2007, 79, 6094-6101.

15. Na, N.; Zhang, C.; Zhao, M.; Zhang, S.; Yang, C.; Fang, X.; Zhang, X Direct Detection of Explosives on Solid Surfaces by Mass Spectrometry 
with an Ambient Ion Source Based on Dielectric Barrier Discharge, J. Mass Spectrom. 2007, 42, 1079-1085.

16. Van Berkel, G. J.; Kertesz, V.; Koeplinger, K. A.; Vavrek, M.; Kong, A. T. Liquid Microjunction Surface Sampling Probe Electrospray Mass Spectrometry for Detection of Drugs and Metabolites in Thin Tissue Sections. J. Mass Spectrom. 2008, 43, 500-508.

17. Chen, H.; Talaty, N.; Takats, Z.; Cooks, R. G. Desorption Electrospray Ionization Mass Spectrometry for High-Throughput Analysis of Pharmaceutical Samples in the Ambient Environment. Anal. Chem. 2005, 77, 6915-6927.

18. Weston, D. J.; Bateman, R.; Wilson, I. D.; Wood, T. R.; Creaser, C. S. Direct Analysis of Pharmaceutical Drug Formulations Using Ion Mobility Spectrometry/Quadrupole-Time-of-Flight Mass Spectrometry Combined with Desorption Electrospray Ionization. Anal. Chem. 2005, $77,7572-7580$

19. Williams, J. P.; Scrivens, J. H. Rapid Accurate Mass Desorption Electrospray Ionization Tandem Mass Spectrometry of Pharmaceutical Samples. Rapid Commun. Mass Spectrom. 2005, 19, 3643-3650.

20. Kauppila, T.; Wiseman, J. M.; Ketola, R. A.; Kotiaho, T.; Cooks, R. G.; Kostiainen, R. Desorption Electrospray Ionization Mass Spectrometry for the Analysis of Pharmaceuticals and Metabolites. Rapid Commun. Mass Spectrom. 2006, 20, 387-392.

21. Jackson, A. U.; Werner, S. R.; Talaty, N.; Song, Y.; Campbell, K.; Cooks, R. G.; Morgan, J. A. Targeted Metabolomic Analysis of Escherichia coli by Desorption Electrospray Ionization and Extractive Electrospray Ionization Mass Spectrometry. Anal. Biochem. 2008, 375, 272-281.

22. Rodriguez-Cruz, S. E. Rapid Analysis of Controlled Substances Using Desorption Electrospray Ionization Mass Spectrometry. Rapid Commun. Mass Spectrom. 2006, 20, 53-60.

23. Leuthold, L. A.; Mandscheff, J. F.; Fathi, M.; Giroud, C.; Augsburger, M.; Varesio, E.; Hopfgartner, G. Desorption Electrospray Ionization Mass Spectrometry: Direct Toxicological Screening and Analysis of Illicit Ecstasy Tablets. Rapid Commun. Mass Spectrom. 2006, 20, 103-110.

24. Takats, Z.; Cotte-Rodriguez, I.; Talaty, N.; Chen, H.; Cooks, R. G. Direct Trace Level Detection of Explosives on Ambient Surfaces by Desorption Electrospray Ionization Mass Spectrometry. Chem. Commun. 2005, 15, 1950-1952.

25. Cotte-Rodriguez, I.; Chen, H.; Cooks, R. G. Rapid Trace Detection of Triacetone Triperoxide (TATP) by Complexation Reactions during Desorption Electrospray Ionization. Chem. Commun 2006, 9, 953-955.

26. Cotte-Rodriguez, I.; Hernandez-Soto, H.; Chen, H.; Cooks, R. G. In Situ Trace Detection of Peroxide Explosives by Desorption Electrospray Ionization and Desorption Atmospheric Pressure Chemical Ionization. Anal. Chem. 2008, 80, 1512-1519.

27. D'Agostino, P. A.; Hancock, J. R.; Chenier, C. L.; Lepage, C. R. Liquid Chromatography Electrospray Tandem Mass Spectrometric and Desorption Electrospray Ionization Tandem Mass Spectrometric Analysis of Chemical Warfare Agents in Office Media Typically Collected during a Forensic Investigation. J. Chromatogr. A 2006, 1110, 86-94.

28. Talaty, N.; Takats, Z.; Cooks, R. G. Rapid in Situ Detection of Alkaloids in Plant Tissue under Ambient Conditions Using Desorption Electrospray Ionization. Analyst 2005, 130, 1624-1633.

29. Wiseman, J. M.; Ifa, D. R.; Song, Q.; Cooks, R. G. Tissue Imaging at Atmospheric Pressure Using Desorption Electrospray Ionization (DESI) Mass Spectrometry. Angew. Chem. Int. Ed. 2006, 45, 7188-7192.

30. Van Berkel, G. J.; Ford, M. J.; Deibel, M. A. Thin-Layer Chromatography and Mass Spectrometry Coupled Using Desorption Electrospray Ionization. Anal. Chem. 2005, 77, 1207-1215.

31. Chen, H.; Cotte-Rodriguez, I.; Cooks, R. G. cis-Diol Functional Group Recognition by Reactive Desorption Electrospray Ionization (DESI). Chem. Commun. 2006, 6, 597-599.

32. Mulligan, C. C.; MacMillan, D. K.; Noll, R. J.; Cooks, R. G. Fast Analysis of High-Energy Compounds and Agricultural Chemicals in Water with Desorption Electrospray Ionization Mass Spectrometry. Rapid Commun. Mass Spectrom. 2007, 21, 3729-3736.

33. Haddad, R.; Sparrapan, R.; Kotiaho, T.; Eberlin, M. N. Easy Ambient Sonic-Spray Ionization-Membrane Interface Mass Spectrometry for Direct Analysis of Solution Constituents. Anal. Chem. 2008, 80, 898-903.

34. Shin, Y. S.; Drolet, B.; Mayer, R.; Dolence, K.; Basile, F. Desorption Electrospray Ionization-Mass Spectrometry of Proteins. Anal. Chem. 2007, 79, 3514-3518.

35. Huang, G.; Chen, H.; Zhang, X.; Cooks, R. G.; Ouyang, Z. Rapid Screening of Anabolic Steroids in Urine by Reactive Desorption Electrospray Ionization. Anal. Chem. 2007, 79, 8327-8332.

36. Nyadong, L.; Green, M. D.; De Jesus, V. R.; Newton, P. N.; Fernandez, F. M. Reactive Desorption Electrospray Ionization Linear Ion Trap Mass Spectrometry of Latest-Generation Counterfeit Antimalarials via Noncovalent Complex Formation. Anal. Chem. 2007, 79, 2150-2157.

37. Takáts, Z.; Wiseman, J. M.; Gologan, B.; Cooks, R. G. Electro-sonic Spray Ionization-a Gentle Technique or Generating Folded Proteins and Protein Complexes in the Gas Phase and Studying Ion-Molecule Reactions at Atmospheric Pressure. Anal. Chem. 2004, 76, 4050-4058.

38. Zhang, Z.; Marshall, A. A Universal Algorithm for Fast and Automated Charge State Deconvolution of Electrospray Mass-to-Charge Ratio Spectra. J. Am. Soc. Mass Spectrom. 1998, 9, 225-233.

39. Zhou, F.; Berkel, G. J. V. Electrochemistry Combined Online with Electrospray Mass Spectrometry. Anal. Chem. 1995, 67, 3643-3649.

40. Myung, S.; Wiseman, J. M.; Valentine, S. J.; Takats, Z.; Cooks, R. G.; Clemmer, D. E. Coupling Desorption Electrospray Ionization with Ion Mobility/Mass Spectrometry for Analysis of Protein Structure: Evi- dence for Desorption of Folded and Denatured States. J. Phys. Chem. B 2006, 110, 5045-5051.

41. Huang, L. Q.; Paiva, A.; Bhat, R.; Wong, M. Characterization of Large, Heterogeneous Proteins by Electrospray Ionization-Mass Spectrometry. J. Am. Soc. Mass Spectrom. 1996, 7, 1219-1226.

42. Chowdhury, S. K.; Katta, V.; Chait, B. T. Proceedings of the 38th ASMS Conference on Mass Spectrometry and Allied Topics; Tucson, AZ, June, 1990; pp 138-139.

43. Henry, K. D.; Wang, B. H.; Williams, E. R. Proceedings of the 38th ASMS Conference on Mass Spectrometry and Allied Topics; Tucson, AZ, June, 1990; pp 443-434.

44. Hirayama, K.; Akashi, S.; Furuya, M.; Fukuhara, K. Rapid Confirmation and Revision of the Primary Structures of Bovine Serum Albumin by ESIMS and FRIT-FAB LC/MS. Biochem. Biophys. Res. Commun. 1990, 173, 639-646.

45. Feng, R.; Konishi, Y. Bell, A. W. High Molecular Weight Determination and Variation Characterization of Proteins Up to $80 \mathrm{Ku}$ by Ionspray Mass-Spectrometry. J. Am. Soc. Mass Spectrom. 1991, 2, 387-401.

46. Carpenter, J. F.; Chang, B. S.; Randolph, T. W. Physical Damage to Proteins during Freezing, Drying, and Rehydration. Biotech. Pharm. Aspects. 2004, 2, 423-442.

47. Kaur-Atwal, G.; Weston, D. J.; Green, P. S.; Crosland, S.; Bonner, P. L. R.; Creaser, C. S. Analysis of Tryptic Peptides Using Desorption Electrospray Ionization Combined with Ion Mobility Spectrometry/Mass Spectrometry. Rapid Commun. Mass Spectrom. 2007, 21, 1131-1138.

48. Kauppila, T. J.; Talaty, N.; Kuuranne, T.; Kotiaho, T.; Kostiainen, R.; Cooks, R. G. Rapid Analysis of Metabolites and Drugs of Abuse from Urine Samples by Desorption Electrospray Ionization-Mass Spectrometry. Analyst 2007, 132, 868-875.

49. Jackson, A. U.; Talaty, N.; Cooks, R. G.; Van Berkel, G. J. Salt Tolerance of Desorption Electrospray Ionization (DESI). J. Am. Soc. Mass Spectrom. 2007, 18, 2218-2225.

50. Kumazawa, T.; Hasegawa, C.; Lee, X.-P.; Hara, K.; Seno, H.; Suzuki, O. Sato, K. Simultaneous Determination of Methamphetamine and Amphetamine in Human Urine Using Pipette Tip Solid-Phase Extraction and Gas Chromatography-Mass Spectrometry. J. Pharm. Biomed. Anal. 2007, 44, 602-607.

51. Al-Dirbashi, O.; Kuroda, N.; Akiyama, S.; Nakashima, K. High-Performance Liquid Chromatography of Methamphetamine and Its Related Compounds in Human Urine Following Derivatization with Fluorescein Isothiocyanate. J. Chromatogr. B 1997, 695, 251-258.

52. Alnajjar, A.; Butcher, J. A.; McCord, B. Determination of Multiple Drugs of Abuse in Human Urine Using Capillary Electrophoresis with Fluorescence Detection. Electrophoresis 2004, 25, 1592-1600.

53. Ramseier, A.; Siethoff, C.; Caslavska, J.; Thormann, W. Confirmation Testing of Amphetamines and Designer Drugs in Human Urine by Capillary Electrophoresis-Ion Trap Mass Spectrometry. Electrophoresis 2000, 21, 380-387.

54. Cone, E. J. Saliva Testing for Drugs of Abuse. Ann. New York Acad. Sci. 1993, 694, 91-127.

55. Van Berkel, G. J.; McLuckey, S. A.; Glish, G. L. Electrochemical Origin of Radical Cations Observed in Electrospray Ionization Mass Spectra. Anal. Chem. 1992, 64, 1586-1593.

56. Xu, X.; Nolan, S. P.; Cole, R. B. Electrochemical Oxidation and Nucleophilic Addition Reactions of Metallocenes in Electrospray Mass Spectrometry. Anal. Chem. 1994, 66, 119-125.

57. Van Berkel, G. J.; Zhou, F. Characterization of an Electrospray Ion Source as a Controlled-Current Electrolytic Cell. Anal. Chem. 1995, 67, 2916-2923.

58. Wesdemiotis, C.; Zhang, M. Y.; McLafferty, F. W. Distinctive IonMolecule Reactions of $\mathrm{C}_{4} \mathrm{H}_{4}{ }^{+}$Isomers with Ammonia. Org. Mass Spectrom. 1991, 26, 671 .

59. Nibbering, N. M. M. Gas-Phase Ion/Molecule Reactions as Studied by Fourier Transform Ion Cyclotron Resonance. Acc. Chem. Res. 1990, 23, 279-285.

60. Kruppa, M.; Konig, B. Reversible Coordinative Bonds in Molecular Recognition. Chem. Rev. 2006, 106, 3520-3560.

61. Anai, T.; Nakata, E.; Koshi, Y.; Ojida, A.; Hamachi, I. Design of a Hybrid Biosensor for Enhanced Phosphopeptide Recognition Based on a Phosphoprotein Binding Domain Coupled with a Fluorescent Chemosensor. J. Am. Chem. Soc. 2007, 129, 6232-6239.

62. Hambitzer, G.; Heitbaum, J. Electrochemical Thermospray Mass Spectrometry. Anal. Chem. 1986, 58, 1067-1070.

63. Barber, M.; Bordoli, R. S.; Elliott, G.; Sedgwick, R. D.; Tyler, A. N. Fast Atom Bombardment Mass Spectrometry. Anal. Chem. 1982, 54, 645A657A.

64. Bond, A. M.; Colton, R.; D'Agostino, A.; Downard, A. J.; Traeger, J. C. A Role for Electrospray Mass Spectrometry in Electrochemical Studies. Anal. Chem. 1995, 67, 1691-1695.

65. Deng, H.; Van Berkel, G. J.; Takano, H.; Gazda, D.; Porter, M. D. Electrochemically Modulated Liquid Chromatography Coupled with On-Line with Electrospray Mass Spectrometry. Anal. Chem. 2000, 72, 2641-2647.

66. Lu, W.; Xu, X.; Cole, R. B. On-Line Linear Sweep VoltammetryElectrospray Mass Spectrometry, Anal. Chem. 1997, 1997, 2478-2484.

67. Permentier, H. P.; Bruins, A. P. Electrochemical Oxidation and Cleavage of Proteins with On-Line Mass Spectrometric Detection: Ddevelopment of an Instrumental Alternative to Enzymatic Protein Digestion. J. Am. Soc. Mass Spectrom. 2004, 15, 1707-1716. 